Original Research Paper

\title{
Optimization of Key Technology for Instant Sea Cucumber Processing through Fuzzy Evaluation and Response Surface Methodology
}

\author{
${ }^{1,2}$ Jianfeng Sun, ${ }^{1}$ Tianshu Yang, ${ }^{1}$ Qian Liu and ${ }^{1}$ Zhaoping Sun \\ ${ }^{1}$ College of Food Science and Technology, Agricultural University of Hebei, Baoding 071000, China \\ ${ }^{2}$ Engineering Technology Research Center for Processing of Agricultural Products of Hebei Province, Baoding 071000, China
}

Article history

Received: 28-04-2017

Revised: $13-06-2017$

Accepted: 23-06-2017

Corresponding Author:

Jianfeng Sun

College of Food Science and

Technology, Agricultural

University of Hebei, Baoding

071000, China

Email: causunjf@126.com causunjf@hebau.edu.cn

\begin{abstract}
The original flavor of instant sea cucumber products can be retained and these products consequently show good market potential. In this study, the key processing technique for instant sea cucumber was optimized on the basis of single factor through Box-Behnken response surface test method by using collagen and polysaccharide contents and fuzzy mathematics sensory score as response values. Results showed that cooking time, cooking temperature, sterilization time and sterilization temperature significantly affected the overall quality and sensory quality of instant sea cucumber products. The optimum processing conditions were as follows: Cooking time, $17 \mathrm{~min}$; cooking temperature, $83^{\circ} \mathrm{C}$; sterilization time, $10 \mathrm{~min}$; and sterilization temperature, $103^{\circ} \mathrm{C}$. Under these conditions, the collagen content, polysaccharide concentration and sensory evaluation were $5.263 \pm 0.020 \%$, $1.021 \pm 0.068 \%$ and $97.27 \pm 0.85$, respectively and these findings were consistent with the predicted values. This study revealed that the nutrient components of instant sea cucumber are efficiently preserved and thus provided technical guarantee for the processing and production of instant sea cucumber.
\end{abstract}

Keywords: Instant Sea Cucumber, Fuzzy Evaluation, Response Surface Method, Collagen, Acid Polysaccharide

\section{Introduction}

Sea cucumber (Stichopus japonicus), which is an invertebrate belonging to Holothuroidea under Echinodermata, is a well-known Chinese traditional seafood because of its rich nutritional value and dietary health function (Eriksson and Clarke, 2015; Bai et al., 2013; Wen et al., 2010). More than 1,100 species of sea cucumber exist worldwide; of these species, about 140 kinds are found in China and 20 kinds are used as food sources (Conand and Byrne, 1993). Sea cucumber is composed of high protein, low fat and low cholesterol contents and highly bioactive ingredients (Lawrence et al., 2010; Bordbar et al., 2011; Mamelona et al., 2009), including saponins, cerebrosides (La et al., 2012), collagen and acid polysaccharides. These bioactive components exhibit anti-tumor, anticoagulation, antiaging, anti-fungal, hypolipidemic and anti-diabetes properties; these components can also alleviate pain, improve immunity, prevent and treat rheumatoid arthritis and induce other beneficial effects (Bordbar et al., 2011). Sea cucumbers exposed to high temperatures or exogenous conditions, such as oil, water, or strong oxidants, contain autoenzymes that can cause a "skin" reaction (Zheng et al., 2010). Therefore, these organisms should be handled immediately after capture. The original flavor of instant sea cucumber products can be retained, they can be easily consumed and stored and they can provide good market prospects (Toral-Grand et al., 2008).

With fast-paced lifestyle and improvements in quality of life, demands for high-quality instant food have become urgent (Charunuch et al., 2011). Key processing technologies for instant seafood products include cooking, stew system, heavy soup cooking and other methods. These processes optimize the texture, sensory or nutrition and other single indicators of sea cucumber products but fail to improve their palatability, nutrition and appearance. For example, high-temperature and high-pressure processing easily degrades collagen gel and consequently induces nutrient loss through water exchange. Collagen constitutes $70 \%$ of proteins in sea cucumber and polysaccharide is an important bioactive ingredient of sea cucumbers (Saito et al., 2002). Sensory score is the relevant index of the general optimization process. In our 
study, the appropriate parameters of instant sea cucumber processing were determined through single-factor and response surface analysis with Box-Behnken design by using collagen protein and polysaccharide contents and sensory scores as response values.

\section{Materials and Methods}

Fresh sea cucumbers were purchased from the aquatic product market of Qinhuangdao in Hebei Province. L-hydroxyproline (Batch number: B21928) and D-fucose (Batch number: B25632) standards were obtained from Shanghai Source Leaves, Biological Technology Co., Ltd. Hydrochloric acid, sulfuric acid, perchloric acid, isopropyl alcohol, two of chloramine T dimethylamino benzaldehyde, citric acid, 95\% ethanol and $30 \%$ hydrogen peroxide were of analytical grade.

\section{Processing Technology for Instant Fresh Sea Cucumber}

The internal organs of fresh sea cucumber were removed (from the abdomen to the anus to the front of the body to cut $1 / 4-1 / 3)$, hot and stereotypes $\left(85-95^{\circ} \mathrm{C}, 2\right.$ $\min )$. The sea cucumbers were then seasoned and cooked. After the sea cucumbers were sterilized through back pressure by using an RS-50L intelligent pressure high-temperature cooking pot (Guangzhou Lonbon Science and Technology Co., Ltd.), the product was vacuum-packed with a DQB-360W double chamber vacuum packaging machine (Shanghai Qingpa Food Packaging Machinery Co., Ltd.). The effects of different processing conditions on the sensory traits and quality of the sea cucumber products were investigated. Secondary seaweeds of the sea cucumber were removed and placed in a dressing solution at $60,70,80,90$ and $100^{\circ} \mathrm{C}$ in cooking liquid for $5,10,15,20$ and 25 min, respectively. They were then vacuumed through $9.0 \times 10^{4} \mathrm{~Pa}$ vacuum packaging at $95,105,115$ and $121^{\circ} \mathrm{C}$ back pressure sterilization and pot sterilization for 5, 10, 15 and $20 \mathrm{~min}$ to prepare instant sea cucumber products. The following parameters were set to season the pretreatment sea cucumbers: Water ratio of 1:3, $42.0 \mathrm{~g}$ per $1 \mathrm{~kg}$ seasoning liquid containing white sugar; $6.0 \mathrm{~g} \mathrm{MSG} ; 24.0 \mathrm{~mL}$ soy sauce; $24.0 \mathrm{~g}$ salt; $3.6 \mathrm{~g}$ ginger powder; $3.6 \mathrm{~g}$ allspice; $4.8 \mathrm{~g}$ star anise; $6 \mathrm{~mL}$ white vinegar; $9.6 \mathrm{~mL}$ cooking wine; and $6 \mathrm{~g}$ chicken bouillon. The collagen and polysaccharide contents of the sea cucumbers were prepared and analyzed (Yao, 2013).

\section{Determination of Collagen and Polysaccharide Contents}

\section{Preparation of L-Hydroxyproline Standard Curve}

The appropriate amount of L-hydroxyproline was weighed and formulated with $100 \mu \mathrm{g} \mathrm{mL}^{-1}$ of the stock solution. The stock solution was absorbed at $0.00,0.60$,
$1.20,1.80,2.40$ and $3.00 \mathrm{~mL}$ in a $10 \mathrm{~mL}$ volumetric flask and constant volume with solution concentrations of 0.0 , $6.0,12.0,18.0,24.0$ and $30.0 \mu \mathrm{g} \mathrm{mL}{ }^{-1}$, respectively. In brief, $1 \mathrm{~mL}$ of this solution was separated and added with $1 \mathrm{~mL}$ of buffer solution $(\mathrm{pH} 6.0)$ and $1 \mathrm{~mL}$ of chloramine $\mathrm{T}$ solution. The new solution was shaken and kept at room temperature for $20 \mathrm{~min}$. Afterward, $1 \mathrm{~mL}$ of perchloric acid solution was added and the solution was shaken and kept at room temperature for $10 \mathrm{~min}$. Next, $1 \mathrm{~mL}$ of the reagent was added and the solution was shaken again. The reaction was conducted at $65^{\circ} \mathrm{C}$ for $20 \mathrm{~min}$. The samples were cooled down to room temperature and spectrally scanned at 900-190 nm. Absorbance at $560 \mathrm{~nm}$ was scanned and recorded and the standard curve was plotted to obtain the regression equation (Yao, 2013).

\section{Preparation and Determination of Collagen in Sea Cucumber}

The chopped sea cucumber samples weighing about $1.0 \mathrm{~g}$ were placed in $20 \mathrm{~mL}$ jaws, added with 2 $\mathrm{mL}$ of $6 \mathrm{~mol} \mathrm{~L}^{-1} \mathrm{HCl}$ solution and digested at $130^{\circ} \mathrm{C}$ for $4 \mathrm{~h}$. After the samples were cooled to room temperature, $\mathrm{pH}$ was adjusted to 6.8-7.2. The solution was transferred in a $100 \mathrm{~mL}$ volumetric flask and 1 $\mathrm{mL}$ of the sample solution was obtained and treated according to the hydroxyproline standard. Absorbance values were measured and recorded and the collagen content was calculated according to the resulting Lhydroxyproline standard curve.

\section{Preparation of D-fucose Standard Curve}

The appropriate amount of D-fucose was weighed and formulated with $100 \mu \mathrm{g} \mathrm{mL}^{-1}$ of the stock solution. The stock solution was absorbed at $0.00,0.60,1.20$, $1.80,2.40$ and $3.00 \mathrm{~mL}$ in a plug test tube and added with $1 \mathrm{~mL}$ of water, $0.6 \mathrm{~mL}$ of phenol solution and 3.00 $\mathrm{mL}$ of concentrated hydrochloric acid. The solution was mixed by vortexing and allowed to stand for $20 \mathrm{~min}$ until it cooled down to room temperature. The samples were spectrally scanned in the range of 900-190 $\mathrm{nm}$. The absorbance at $490 \mathrm{~nm}$ was recorded after scanning and the standard curve was plotted to obtain the regression equation (Yao, 2013).

\section{Preparation and Determination of Acid Polysaccharides in Sea Cucumber}

The chopped sea cucumber samples weighing about $3.0 \mathrm{~g}$ were placed in a $100 \mathrm{~mL}$ cone bottle, added with 40 $\mathrm{mL}$ of $3 \% \mathrm{KOH}$ solution and leached for $2 \mathrm{~h}$ by ultrasound. Their $\mathrm{pH}$ was adjusted to 6.8-7.2 by adding 2 $\mathrm{M}$ acetic acid and centrifuged at $8500 \mathrm{r} / \mathrm{min}$ and $4{ }^{\circ} \mathrm{C}$ for $30 \mathrm{~min}$. The supernatant was removed and slowly added with twice the volume of $95 \%$ ethanol. The resulting solution was allowed to stand overnight and then centrifuged at $8000 \mathrm{r} / \mathrm{min}$ for $15 \mathrm{~min}$. The precipitate 
was extracted and added with $10 \mathrm{~mL}$ of distilled water. Afterward, $2 \mathrm{~mL}$ of hydrogen peroxide was added for decolorization. The solution was added with $24 \mathrm{~mL}$ of $95 \%$ ethanol, allowed to stand overnight and centrifuged at $8000 \mathrm{r} / \mathrm{min}$ for $15 \mathrm{~min}$. The sample was baked in an oven with a constant temperature of $50^{\circ} \mathrm{C}$ and the dried sample was prepared as a $200 \mu \mathrm{g} \mathrm{mL} \mathrm{m}^{-1}$ solution. Then, $1 \mathrm{~mL}$ of the sample was obtained and processed according to the fucose standard. The absorbance values were measured and recorded and the polysaccharide content was calculated according to the measured D-fucose standard curve.

\section{Fuzzy Evaluation}

The instant sea cucumber samples were randomly placed in identical sensory panels coded with randomly selected 3-digit numbers prior to the random monadic presentation to each of the 10 evaluator professionals with expertise in sensory assessment. Traditional evaluation results are inaccurate because of the lack of objectivity. Some subjective factors significantly affect sensory evaluation results. However, fuzzy mathematics for comprehensive evaluation can involve different factors in scoring during sensory evaluation and consequently enhance the accuracy of results. Fuzzy mathematics for statistics and data analysis can also reduce accidental errors. Therefore, the sensory evaluation of sea cucumber was performed through fuzzy mathematics comprehensive analysis. The fuzzy evaluation method changes the traditional average scoring system and requires a choice for the evaluation domain $\mathrm{U}=\left(\mathrm{U}_{1}, \mathrm{U}_{2}, \mathrm{U}_{3}\right)=$ (color, flavor, flesh elasticity), comment domain $\mathrm{V}=\left(\mathrm{V}_{1}, \mathrm{~V}_{2}, \mathrm{~V}_{3}, \mathrm{~V}_{4}\right)=$ (very good, fine, ordinary, poor), fuzzy weight vector $\mathrm{X}$
$=\left(X_{1}, X_{2}, X_{3}\right)=(0.45,0.2,0.35)$, grade evaluation matrix $\mathrm{P}=\left(\mathrm{P}_{1}, \mathrm{P}_{2}, \mathrm{P}_{3}, \mathrm{P}_{4}\right)=(100,80,60,40)$ and sensory evaluation indexes (Table 1) (Hu and Xia, 2011).

In this study, fuzzy mathematics comprehensive evaluation was performed through the following threestep membership grade. (i) The sensory evaluation results of each evaluation domain were calculated to build the multiple objective evaluation membership matrix $R_{i}=\left(r_{i 1}, r_{i 2}, r_{i 3}, r_{i 4}\right)$ and obtain the fuzzy evaluation matrix $R=\left(R_{i 1}, R_{i 2}, R_{i 3}\right)^{T}$. (ii) The comprehensive grading vector was $B_{k}=X \times R=\left(X_{1}, X_{2}\right.$, $\left.X_{3}\right)\left(R_{i 1}, R_{i 2}, R_{i 3}\right)^{T}$ and the specific operations of (i) and (ii) were conducted by referring to previous studies (Gao and Fu, 2011; Liu et al., 2012; 2014). (iii) The comprehensive evaluation score of each sample was $\mathrm{S}_{\mathrm{j}}=$ $\mathrm{P} \times \mathrm{B}_{\mathrm{k}}{ }^{\mathrm{T}}=\left(\mathrm{P}_{1}, \mathrm{P}_{2}, \mathrm{P}_{3}, \mathrm{P}_{4}\right)\left(\mathrm{B}_{\mathrm{k} 1}, \mathrm{~B}_{\mathrm{k} 2}, \mathrm{~B}_{\mathrm{k} 3}, \mathrm{~B}_{\mathrm{k} 4}\right)^{\mathrm{T}}$, which can be applied to rank the competition of sea cucumber. In this study, the weight of the color, flavor and flesh elasticity of the sea cucumber represents the average of the mandatory scoring, sequential evaluation and statistical evaluation methods, respectively (Ji, 1991). The analyses were repeated thrice.

\section{Response Surface Test}

The effects of cooking time, cooking temperature, sterilization time and sterilization temperature as independent variables were selected by using single factor. Based on Box-Behnken design principle, four-factor and three-level response surface analyses were conducted by considering collagen and polysaccharide contents and sensory scores as evaluation indexes (Song et al., 2012; Zhu et al., 2016). The factor level design is shown in Table 2 and the analyses were repeated thrice.

Table 1 . Sensory evaluation table

\begin{tabular}{lllll}
\hline Grade & Label & Color & Flavor & Elasticity \\
\hline Great & A & Black & Rich seafood flavor & Soft medium \\
Good & B & Brown & Slightly seafood flavor & Poor palatability \\
Ordinary & C & Yellow-brown & Slightly fishy & General taste \\
Bad & D & Yellow & Fishy & Poor hardness \\
\hline
\end{tabular}

Table 2. Factors and levels used in response surface design

\begin{tabular}{lccc}
\hline & Level & & \\
Factor & -1 & 0 & 15 \\
\hline Cooking time $/$ min & 10 & 80 & 20 \\
Boiling temperature $/{ }^{\circ} \mathrm{C}$ & 70 & 10 & 90 \\
Sterilization time $/$ min & 5 & 105 & 15 \\
Sterilization temperature $/{ }^{\circ} \mathrm{C}$ & 95 & & 115 \\
\hline
\end{tabular}

Table 3. Regression equation of L-Hydroxyproline and D-fucose

\begin{tabular}{llll}
\hline & Regression equation & $\mathrm{R}^{2}$ & Application scope (ug/mL) \\
\hline L-hydroxyproline & $\mathrm{Y}=0.0780 \mathrm{X}+0.0816$ & 0.9938 & $0.00-15.00$ \\
D-fucose & $\mathrm{Y}=0.0093 \mathrm{X}-0.0069$ & 0.9986 & $0.00-30.00$ \\
\hline
\end{tabular}




\section{Results and Analysis}

\section{L-hydroxyproline and D-fucose Standard Curve}

The absorbance was measured at 560 and $490 \mathrm{~nm}$ according to the mass concentration gradient of Lhydroxyproline and D-fucose standards. Using the mass concentration $(\mu \mathrm{g} / \mathrm{mL})$ as the abscissa and the absorbance as the ordinate, we plotted the standard curve. The regression equation is shown in Table 3.

\section{Single Factor Test}

Figure 1 illustrates the effect of different processing conditions on collagen and polysaccharide contents and sensory evaluation. Figure 1A shows that the collagen and polysaccharide contents of instant sea cucumber decreased as sterilization time was prolonged at a cooking time of $20 \mathrm{~min}$, cooking temperature of $80^{\circ} \mathrm{C}$ and sterilization temperature of $121^{\circ} \mathrm{C}$. As cooking time is extended and temperature is increased, collagen fibers gradually thicken, condense, gradually split and disintegrate (Xue, 2006). The sensory score of instant sea cucumber initially increased, subsequently decreased and reached the optimum at a sterilization time of 10 $\min$. Thus, the sterilization time was set to $10 \mathrm{~min}$.

Figure $1 \mathrm{~B}$ indicates that the collagen and polysaccharide contents of instant sea cucumber initially remained unchanged and then decreased as sterilization temperature was increased at a cooking time of $20 \mathrm{~min}$, cooking temperature of $80^{\circ} \mathrm{C}$ and sterilization time of $5 \mathrm{~min}$. The collagen and polysaccharide structures of instant sea cucumber were gradually destroyed and broken into small peptides and monosaccharides or disaccharides as sterilization temperature increased. Consequently, collagen and polysaccharide lost their potency. The sensory score of sea cucumber also gradually increased. The elasticity, hardness and palatability of sea cucumber improved possibly because of the high-temperature and highpressure stew system. Therefore, the sterilization temperature of $115^{\circ} \mathrm{C}$ was appropriate.

Figure 1C reveals that the collagen and polysaccharide contents of the instant sea cucumber initially increased and then decreased as cooking time was prolonged at a cooking temperature of $80^{\circ} \mathrm{C}$, germination time of $5 \mathrm{~min}$ and sterilization temperature of $121^{\circ} \mathrm{C}$. Higher levels were obtained when cooking time was set to $15 \mathrm{~min}$ because of the increase in collagen and polysaccharide levels due to the accumulation and contraction of sea cucumber in early cooking stages. The moisture content of instant sea cucumber almost remained unchanged and the collagen and polysaccharide contents gradually decreased as cooking time was prolonged. The collagen and polysaccharide contents of sea cucumber were not significantly different when the cooking time was 10 and $15 \mathrm{~min}$. The sensory score of instant sea cucumber continuously increased as cooking time was extended. The collagen and polysaccharide contents of instant sea cucumber were sharply reduced when cooking time was more than $15 \mathrm{~min}$. Therefore, the suitable cooking time was $10 \mathrm{~min}$.

Figure 1D shows that the collagen and polysaccharide contents and sensory score of instant sea cucumber initially increased and then decreased as cooking temperature increased at a cooking time of 20 min, germination time of $5 \mathrm{~min}$ and sterilization temperature of $121^{\circ} \mathrm{C}$. The polysaccharide content of instant sea cucumber no longer changed when cooking temperature reached $80^{\circ} \mathrm{C}$. The highest collagen content and sensory score of instant sea cucumber were obtained when the temperature reached 70 and $90^{\circ} \mathrm{C}$. These values subsequently declined. Therefore, the appropriate cooking temperature was $80^{\circ} \mathrm{C}$.

\section{Response Surface Design and Result Analysis}

According to the single factor test, the significant test factors were greater. Based on Box-Behnken principle, four factors and three levels of cooking time (29 test points) included cooking temperature, sterilization time and bactericidal temperature as independent variables, whereas collagen and polysaccharide contents and sensory score were set as response values. The experimental design and results are shown in Table 4.

Variance analysis was performed on the regression model and the results are shown in Table 5. Three groups of model factors were $\mathrm{p}<0.0001$, which indicated that the factor regression model exhibited a significant difference $(p<0.01)$. In the loss of the proposed $\mathrm{P}=0.0832$ (collagen), $\mathrm{P}=0.08718$ (polysaccharide) and $\mathrm{P}=0.1282$ (sensory evaluation), the difference was not significant and these data suggested that the model was stable and the error was random. The three models could predict the effects of different processing conditions on the collagen and polysaccharide contents and sensory score of instant sea cucumber.

\section{Establishment of Mathematical Model and Significance Test}

The polynomial regression model of the collagen and polysaccharide contents, sensory score and relevant factors were obtained through the multiple fitting regression of the experimental data. The collagen and polysaccharide contents and sensory score of instant sea cucumber were used as the response values, whereas cooking time $\left(\mathrm{X}_{1}\right)$, cooking temperature $\left(\mathrm{X}_{2}\right)$, sterilization time $\left(\mathrm{X}_{3}\right)$ and sterilization temperature $\left(\mathrm{X}_{4}\right)$ were considered as independent variables. The secondary regression model is shown in Table 6 . 

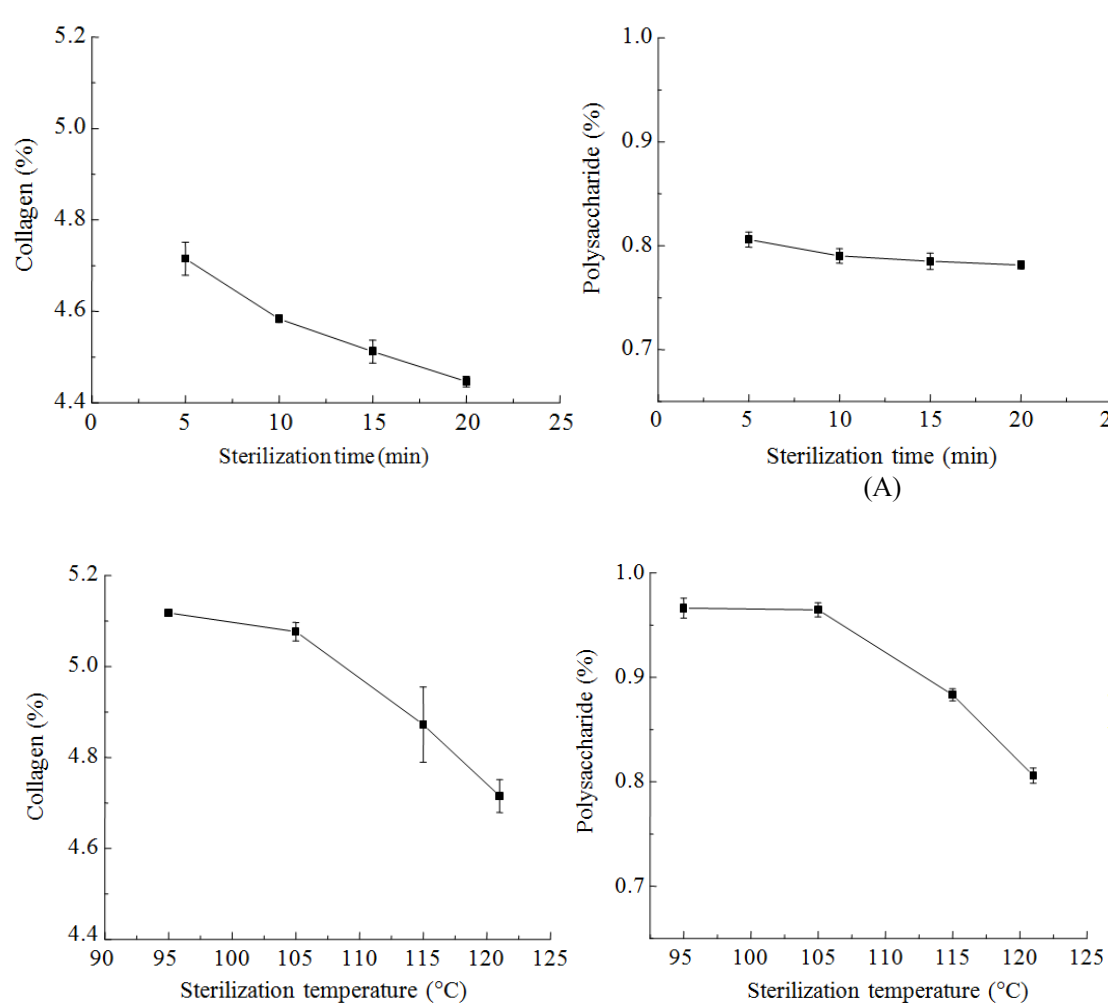

(B)
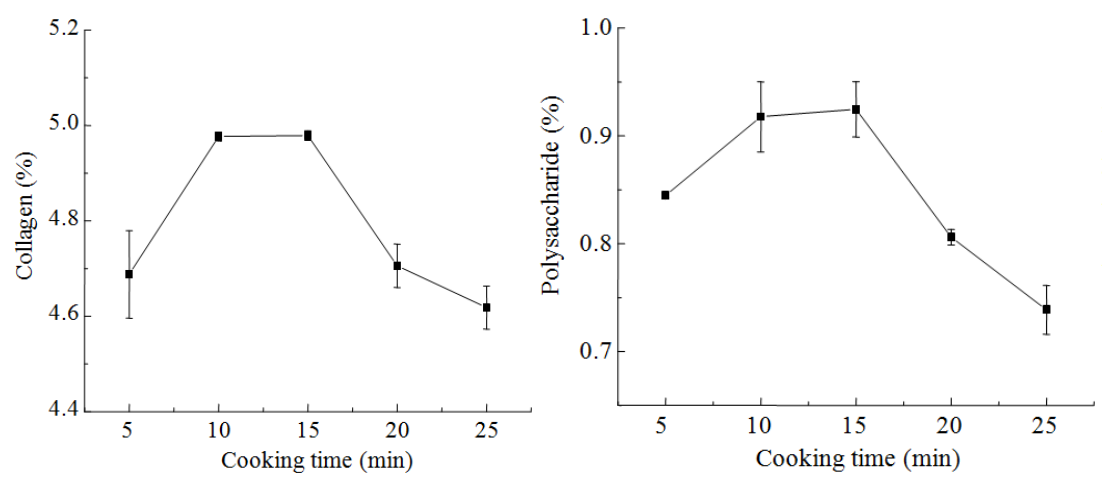

(C)

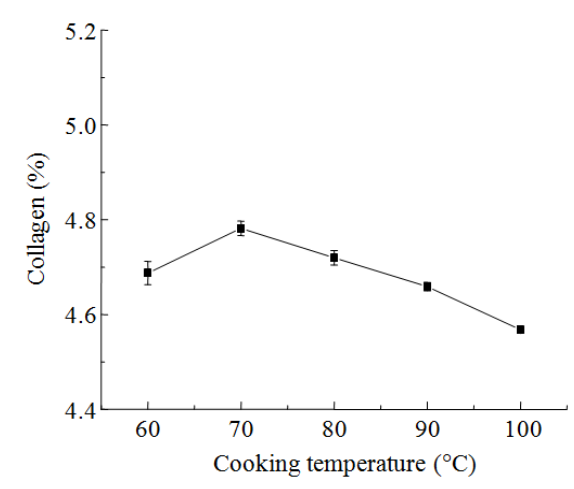

(A)
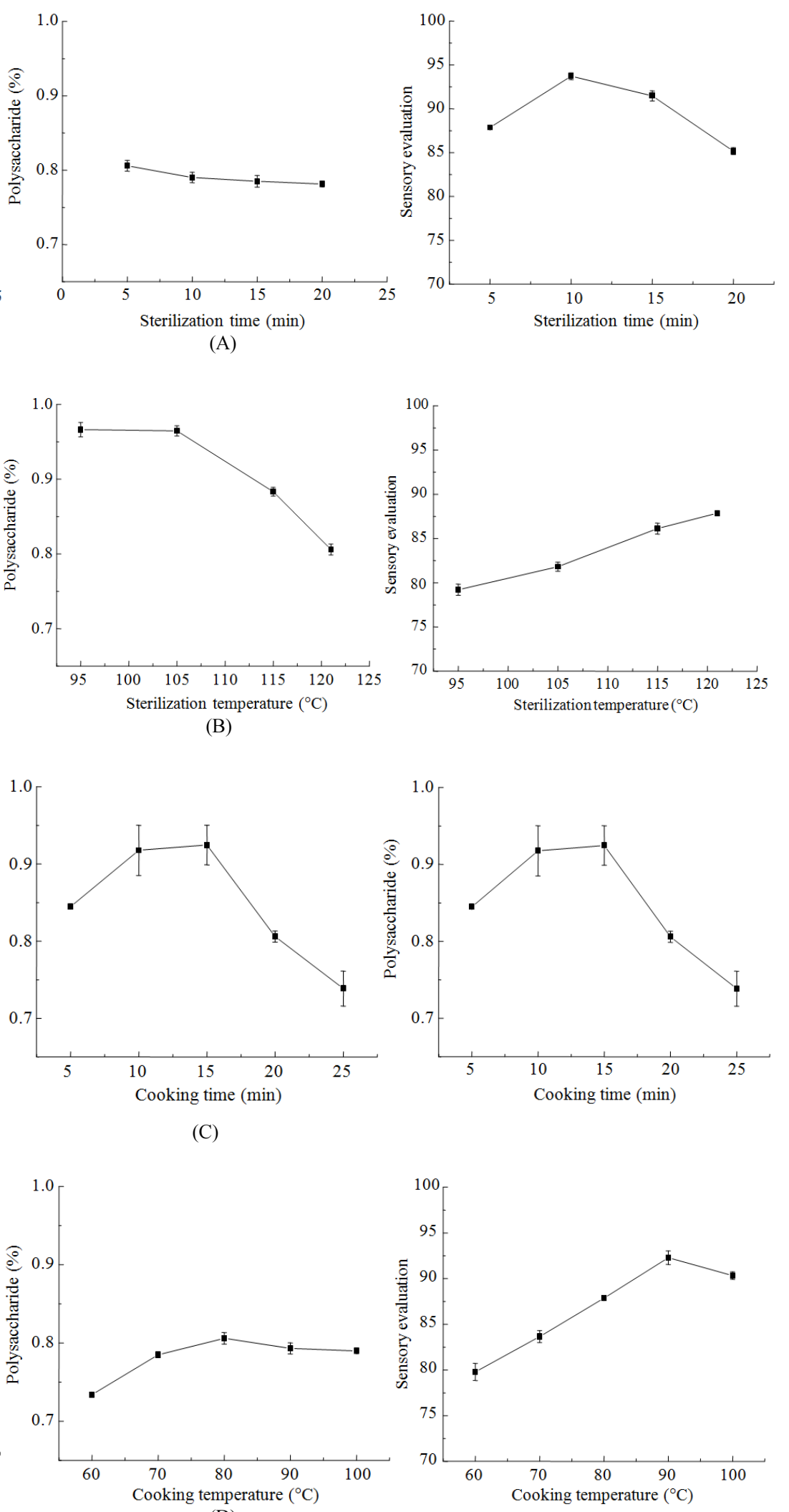

(D)

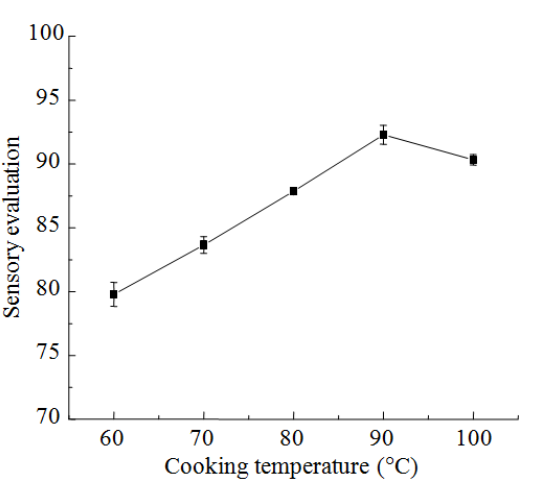

Cooking temperature $\left({ }^{\circ} \mathrm{C}\right)$

Fig. 1. Effect of different processing conditions on the collagen and polysaccharide contents and the sensory evaluation 

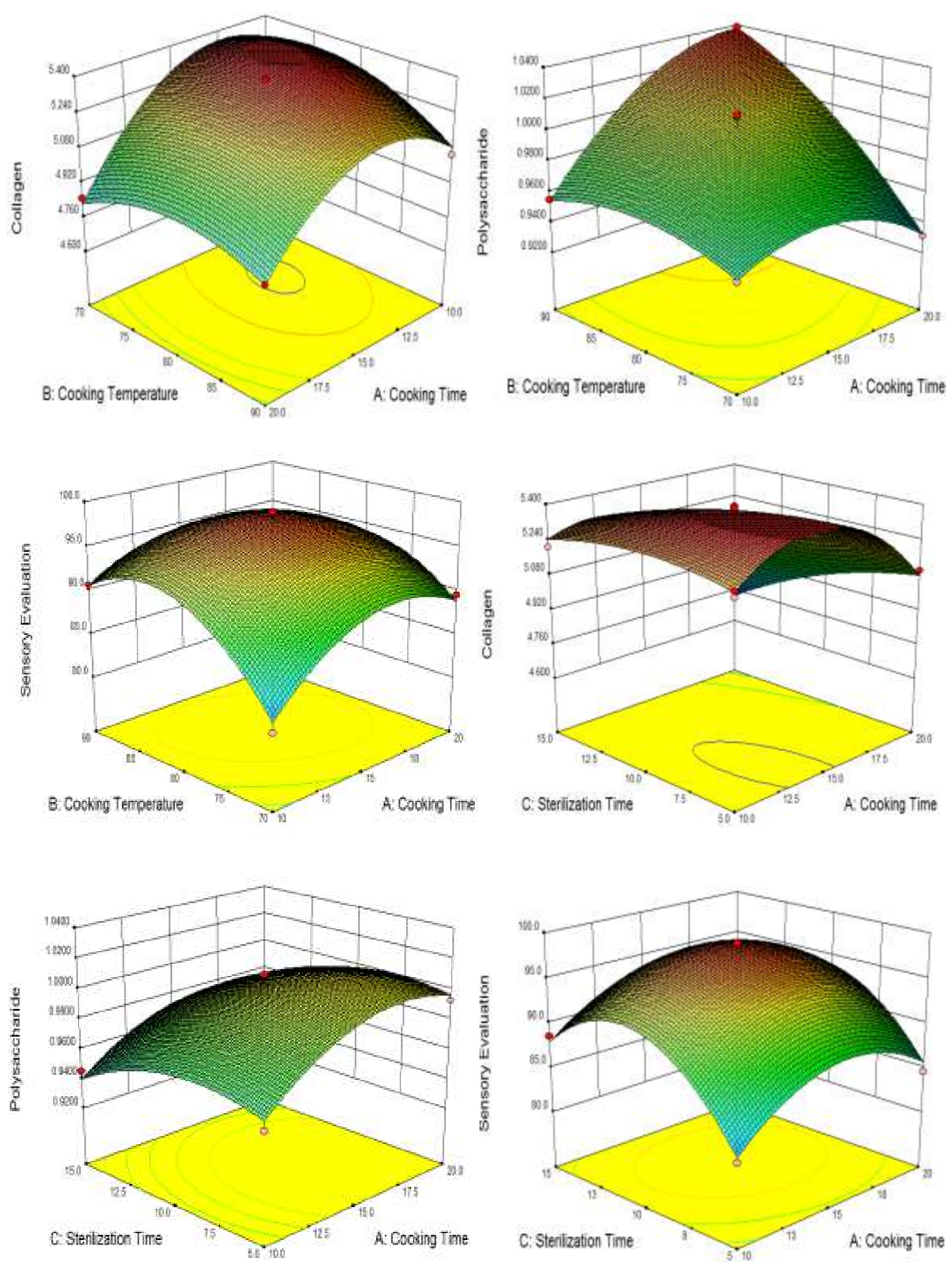

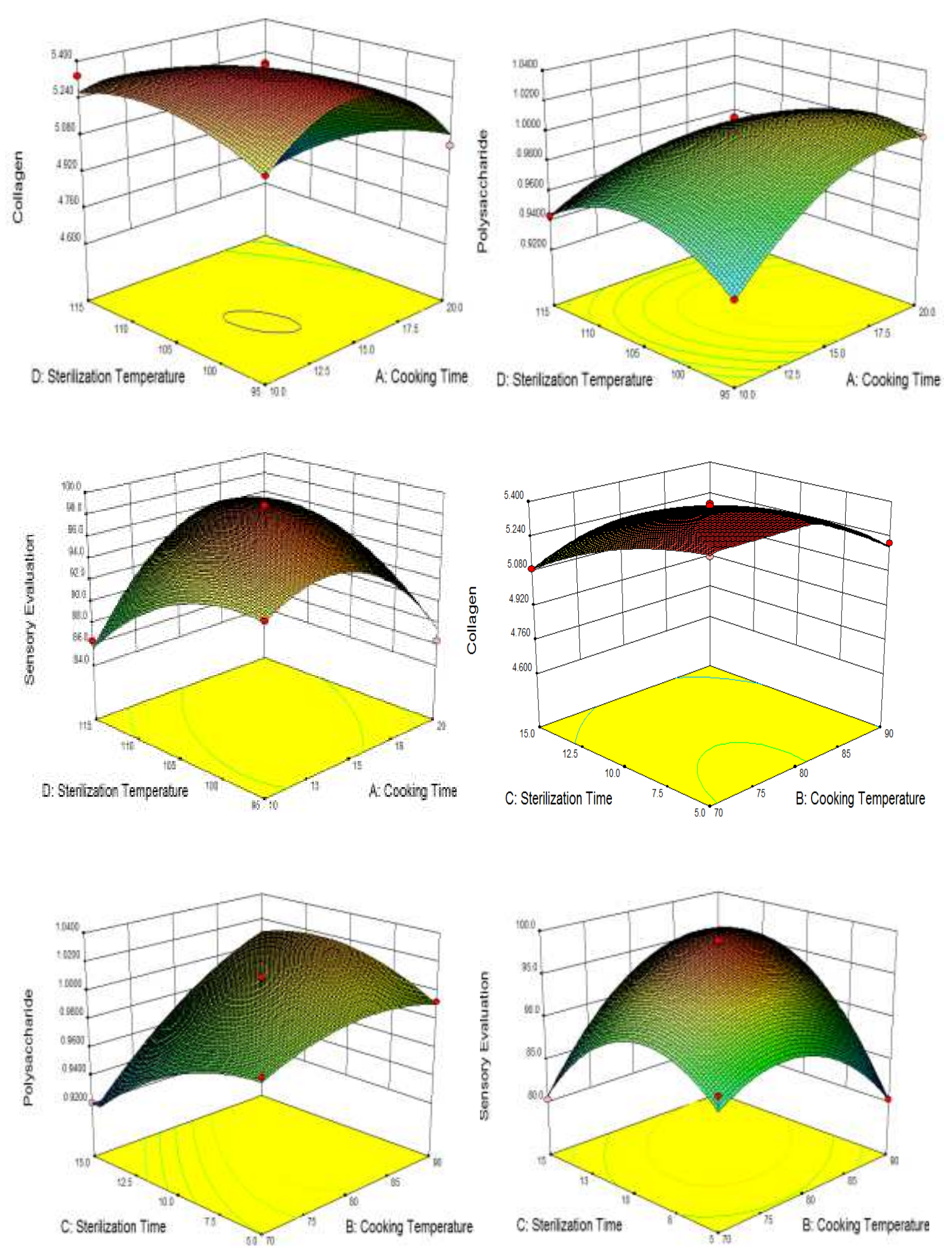

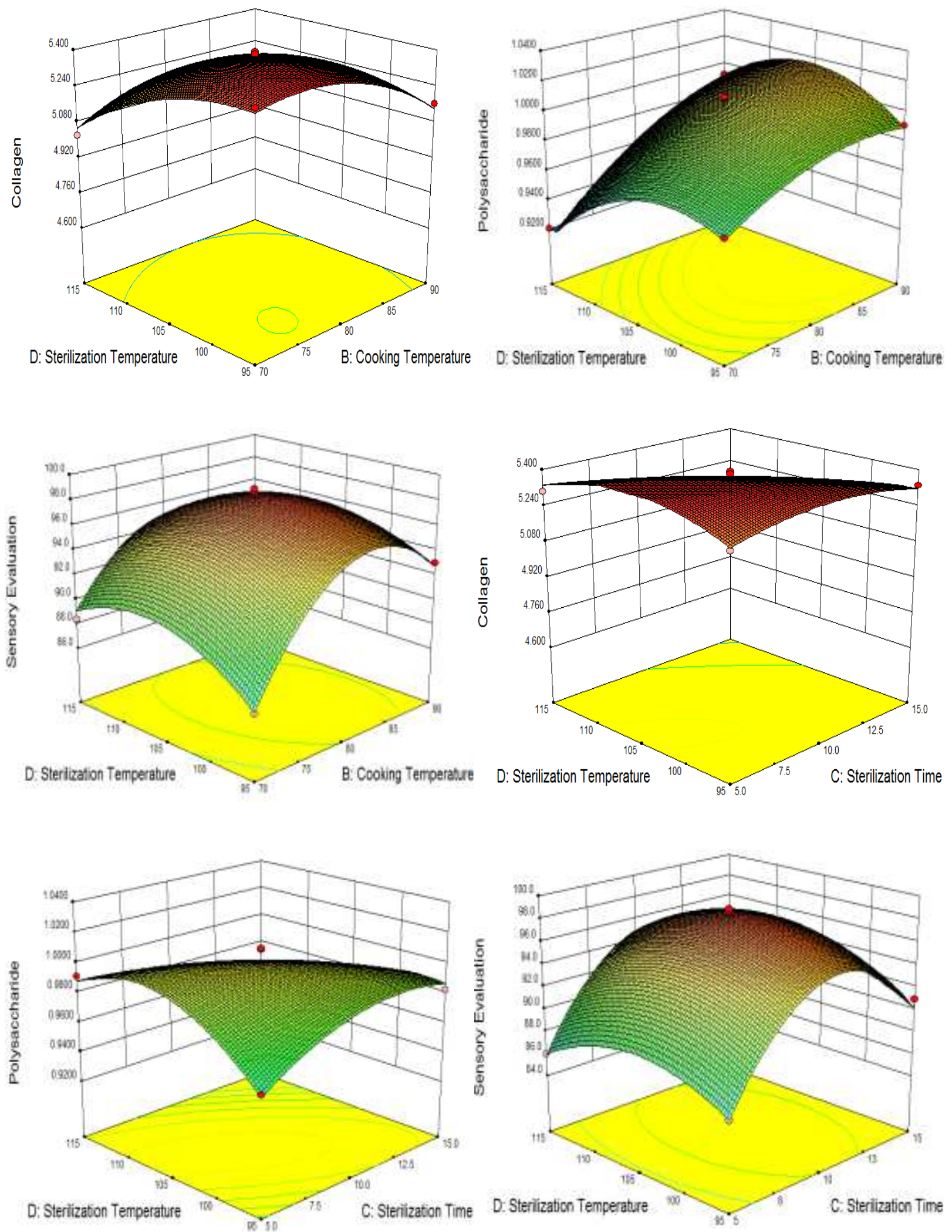

Fig. 2. Response surface plots for the effect of independent variables on response variables 
Table 4. Experimental designs and results for response surface design

\begin{tabular}{|c|c|c|c|c|c|c|c|}
\hline \multirow{2}{*}{$\begin{array}{l}\text { Experiment } \\
\text { number }\end{array}$} & \multirow{2}{*}{$\begin{array}{l}\text { Cooking } \\
\text { time } \\
(\mathrm{min})\end{array}$} & \multirow{2}{*}{$\begin{array}{l}\text { Boiling } \\
\text { temperature } \\
\left({ }^{\circ} \mathrm{C}\right)\end{array}$} & \multirow{2}{*}{$\begin{array}{l}\text { Sterilization } \\
\text { time (min) }\end{array}$} & \multirow{2}{*}{$\begin{array}{l}\text { Sterilization } \\
\text { temperature } \\
\left({ }^{\circ} \mathrm{C}\right)\end{array}$} & \multicolumn{3}{|l|}{ Experimental data } \\
\hline & & & & & Collagen Protein (\%) & Polysaccharide (\%) & Sensory evaluation \\
\hline 1 & 15 & 80 & 15 & 115 & 4.9550 & 0.9082 & 91.1 \\
\hline 2 & 15 & 70 & 10 & 95 & 5.3811 & 0.9607 & 86.6 \\
\hline 3 & 15 & 90 & 15 & 105 & 5.1560 & 1.0072 & 92.0 \\
\hline 4 & 15 & 80 & 10 & 105 & 5.3481 & 1.0098 & 97.6 \\
\hline 5 & 15 & 90 & 10 & 95 & 5.1652 & 0.9907 & 93.0 \\
\hline 6 & 15 & 90 & 10 & 115 & 5.0850 & 0.9923 & 89.5 \\
\hline 7 & 15 & 70 & 5 & 105 & 5.3860 & 0.9828 & 88.3 \\
\hline 8 & 15 & 80 & 5 & 95 & 5.2910 & 0.9582 & 86.5 \\
\hline 9 & 15 & 80 & 15 & 95 & 5.3309 & 0.9826 & 91.0 \\
\hline 10 & 20 & 70 & 10 & 105 & 4.8510 & 0.9310 & 89.6 \\
\hline 11 & 10 & 80 & 5 & 105 & 5.2620 & 0.9528 & 82.5 \\
\hline 12 & 20 & 80 & 5 & 105 & 5.1040 & 0.9928 & 84.6 \\
\hline 13 & 20 & 80 & 10 & 115 & 4.6739 & 0.9438 & 94.6 \\
\hline 14 & 20 & 80 & 10 & 95 & 5.0380 & 0.9962 & 86.3 \\
\hline 15 & 15 & 80 & 10 & 105 & 5.3790 & 0.9945 & 98.9 \\
\hline 16 & 15 & 80 & 10 & 105 & 5.3520 & 0.9986 & 97.2 \\
\hline 17 & 15 & 80 & 5 & 115 & 5.3049 & 0.9914 & 86.0 \\
\hline 18 & 10 & 90 & 10 & 105 & 5.0550 & 0.9550 & 90.7 \\
\hline 19 & 15 & 80 & 10 & 105 & 5.3870 & 1.0090 & 98.6 \\
\hline 20 & 10 & 80 & 10 & 115 & 5.3380 & 0.9438 & 86.3 \\
\hline 21 & 10 & 80 & 10 & 95 & 5.1740 & 0.9362 & 93.9 \\
\hline 22 & 15 & 70 & 10 & 115 & 5.0238 & 0.9133 & 88.4 \\
\hline 23 & 15 & 90 & 5 & 105 & 5.2140 & 0.9928 & 80.2 \\
\hline 24 & 20 & 90 & 10 & 105 & 4.8710 & 1.0380 & 90.0 \\
\hline 25 & 15 & 70 & 15 & 105 & 5.0960 & 0.9101 & 80.2 \\
\hline 26 & 20 & 80 & 15 & 105 & 4.7200 & 0.9752 & 88.7 \\
\hline 27 & 10 & 70 & 10 & 105 & 5.2809 & 0.9490 & 81.9 \\
\hline 28 & 15 & 80 & 10 & 105 & 5.3890 & 0.9975 & 97.5 \\
\hline 29 & 10 & 80 & 15 & 105 & 5.2100 & 0.9452 & 88.7 \\
\hline
\end{tabular}

The coefficient of determination $\left(\mathrm{R}^{2}\right)$, correction fit $\left(\mathrm{RAdj}^{2}\right)$ and Coefficient of Variation (CV) of the regression equation are shown in Table 6 . The collagen, polysaccharide and sensory evaluation models could respectively yield the following values: 96.83, 97.36 and $94.70 \%$ response changes. The experimental data were highly reliable and the test error was small. The model exhibited good fitting degree and high stability, which provided a good mathematical model to optimize high-quality instant sea cucumber products.

\section{Response Surface Analysis}

The data in Table 4 were subjected to quadratic multiple regression fitting by using Design-Expert 8.0.6. The response surface analysis of surface collagen and polysaccharide and the sensory evaluation of instant sea cucumber are shown in Fig. 2. The response images of the two interactions between the two factors indicated that the interaction of the experimental factors was significant. The 3D response surface is the graphical representation of the regression function. These images were obtained by maintaining two of the variables constant, which corresponded to the changes in the collagen and polysaccharide contents and sensory quality under different conditions. The effects of response surface were significant when the curves were steep but were unremarkable when the curves were flat. The most significant interaction effect was sensory score, followed by polysaccharide and collagen contents (Fig. 2). The quadratic polynomial regression model and response surface analysis results demonstrated that the regression model yielded a stable point, with three response values combined the highest point, under the following conditions: Cooking time of 17 min, cooking temperature of $83^{\circ} \mathrm{C}$, sterilization time of $10 \mathrm{~min}$ and sterilization temperature of $103^{\circ} \mathrm{C}$.

\section{Verification Test}

Three sets of repeated tests were conducted under the obtained optimum conditions. The sea cucumber consisted of a collagen content of $(5.263 \pm 0.020 \%)$, a polysaccharide content of $(1.021 \pm 0.068 \%)$ and a sensory score of $97.27 \pm 0.85$ and these findings are consistent with the respective theoretical predictions of 5.270, 1.0163 and 97.00. Therefore, the regression model can be used to describe the influence of each factor on the response value and reliably predict the quality of instant sea cucumber products. 
Jianfeng Sun et al. / American Journal of Biochemistry and Biotechnology 2017, 13 (2): 99.110 DOI: 10.3844/ajbbsp.2017.99.110

Table 5. Analysis of variance for response surface regression model

\begin{tabular}{|c|c|c|c|c|c|}
\hline Variance sources & Sum of squares & Freedom & Mean square & $F$ & $P$ \\
\hline \multicolumn{6}{|l|}{ Collagen protein $(\%)$} \\
\hline Model & 1.140 & 14 & 0.082 & 62.1 & $<0.0001$ \\
\hline $\mathrm{X}_{1}$ (Cooking time) & 0.350 & 1 & 0.350 & 269.62 & $<0.0001$ \\
\hline $\mathrm{X}_{2}$ (Boiling temperature) & 0.019 & 1 & 0.019 & 14.19 & 0.0021 \\
\hline $\mathrm{X}_{3}($ Sterilization time $)$ & 0.100 & 1 & 0.100 & 75.9 & $<0.0001$ \\
\hline $\mathrm{X}_{4}($ Sterilization temperature $)$ & 0.083 & 1 & 0.083 & 63.29 & $<0.0001$ \\
\hline $\mathrm{X}_{1} \mathrm{X}_{2}$ & 0.015 & 1 & 0.015 & 11.51 & 0.0044 \\
\hline $\mathrm{X}_{1} \mathrm{X}_{3}$ & 0.028 & 1 & 0.028 & 20.97 & 0.0004 \\
\hline $\mathrm{X}_{1} \mathrm{X}_{4}$ & 0.070 & 1 & 0.070 & 53.04 & $<0.0001$ \\
\hline $\mathrm{X}_{2} \mathrm{X}_{3}$ & 0.013 & 1 & 0.013 & 10.24 & 0.0064 \\
\hline $\mathrm{X}_{2} \mathrm{X}_{4}$ & 0.019 & 1 & 0.019 & 14.6 & 0.0019 \\
\hline $\mathrm{X}_{3} \mathrm{X}_{4}$ & 0.038 & 1 & 0.038 & 28.94 & $<0.0001$ \\
\hline $\mathrm{X}_{1}^{2}$ & 0.360 & 1 & 0.360 & 276.96 & $<0.0001$ \\
\hline $\mathrm{X}_{2}^{2}$ & 0.084 & 1 & 0.084 & 63.59 & $<0.0001$ \\
\hline $\mathrm{X}_{3}^{2}$ & 0.020 & 1 & 0.020 & 15.14 & 0.0016 \\
\hline $\mathrm{X}_{4}^{2}$ & 0.051 & 1 & 0.051 & 39.1 & $<0.0001$ \\
\hline Regression value & 0.018 & 14 & $1.31 \mathrm{E}-03$ & & \\
\hline Missing item & 0.017 & 10 & $1.69 \mathrm{E}-03$ & 4.4 & 0.0832 \\
\hline residual & $1.53 \mathrm{E}-03$ & 4 & $3.84 \mathrm{E}-04$ & & \\
\hline Total residuals & 1.16 & 28 & & & \\
\hline Polysaccharide $(\%)$ model & 0.031 & 14 & $2.198 \mathrm{E}-003$ & 74.81 & $<0.0001$ \\
\hline $\mathrm{X}_{1}$ (Cooking time) & $3.169 \mathrm{E}-003$ & 1 & $3.169 \mathrm{E}-003$ & 107.86 & $<0.0001$ \\
\hline $\mathrm{X}_{2}$ (Boiling temperature) & $9.026 \mathrm{E}-003$ & 1 & $9.026 \mathrm{E}-003$ & 307.22 & $<0.0001$ \\
\hline $\mathrm{X}_{3}($ Sterilization time $)$ & $1.687 \mathrm{E}-003$ & 1 & $1.687 \mathrm{E}-003$ & 57.44 & $<0.0001$ \\
\hline $\mathrm{X}_{4}$ (Sterilization temperature) & $1.448 \mathrm{E}-003$ & 1 & $1.448 \mathrm{E}-003$ & 49.28 & $<0.0001$ \\
\hline $\mathrm{X}_{1} \mathrm{X}_{2}$ & $2.550 \mathrm{E}-003$ & 1 & $2.550 \mathrm{E}-003$ & 86.81 & $<0.0001$ \\
\hline $\mathrm{X}_{1} \mathrm{X}_{4}$ & $9.000 \mathrm{E}-004$ & 1 & $9.000 \mathrm{E}-004$ & 30.64 & $<0.0001$ \\
\hline $\mathrm{X}_{2} \mathrm{X}_{3}$ & 1.897 E-003 & 1 & $1.897 \mathrm{E}-003$ & 64.56 & $<0.0001$ \\
\hline $\mathrm{X}_{2} \mathrm{X}_{4}$ & $6.003 \mathrm{E}-004$ & 1 & $6.003 \mathrm{E}-004$ & 20.43 & 0.0005 \\
\hline $\mathrm{X}_{3} \mathrm{X}_{4}$ & 2.894 E-003 & 1 & $2.894 \mathrm{E}-003$ & 98.52 & $<0.0001$ \\
\hline $\mathrm{X}_{1}^{2}$ & $2.758 \mathrm{E}-003$ & 1 & $2.758 \mathrm{E}-003$ & 93.87 & $<0.0001$ \\
\hline $\mathrm{X}_{2}^{2}$ & $1.035 \mathrm{E}-003$ & 1 & $1.035 \mathrm{E}-003$ & 35.23 & $<0.0001$ \\
\hline $\mathrm{X}_{3}^{2}$ & $1.575 \mathrm{E}-003$ & 1 & $1.575 \mathrm{E}-003$ & 53.61 & $<0.0001$ \\
\hline $\mathrm{X}_{4}^{2}$ & 4.324 E-003 & 1 & $4.324 \mathrm{E}-003$ & 147.19 & $<0.0001$ \\
\hline Regression value & $4.113 \mathrm{E}-004$ & 14 & $2.938 \mathrm{E}-005$ & & \\
\hline Missing item & $2.135 \mathrm{E}-004$ & 10 & $2.135 \mathrm{E}-005$ & 0.43 & 0.8718 \\
\hline residual & $1.978 \mathrm{E}-004$ & 4 & $4.946 \mathrm{E}-005$ & & \\
\hline Total residuals & 0.031 & 28 & & & \\
\hline Sensory score model & 767.48 & 14 & 54.82 & 36.72 & $<0.0001$ \\
\hline $\mathrm{X}_{1}$ (Cooking time) & 8.07 & 1 & 8.07 & 5.4 & 0.0356 \\
\hline $\mathrm{X}_{2}$ (Boiling temperature) & 35.09 & 1 & 35.09 & 23.5 & 0.0003 \\
\hline $\mathrm{X}_{3}($ Sterilization time $)$ & 46.18 & 1 & 46.18 & 30.93 & $<0.0001$ \\
\hline $\mathrm{X}_{1} \mathrm{X}_{2}$ & 17.98 & 1 & 17.98 & 12.04 & 0.0038 \\
\hline $\mathrm{X}_{1} \mathrm{X}_{4}$ & 62.33 & 1 & 62.33 & 41.75 & $<0.0001$ \\
\hline $\mathrm{X}_{2} \mathrm{X}_{3}$ & 98.8 & 1 & 98.8 & 66.18 & $<0.0001$ \\
\hline $\mathrm{X}_{2} \mathrm{X}_{4}$ & 7.18 & 1 & 7.18 & 4.18 & 0.0457 \\
\hline $\mathrm{X}_{1}^{2}$ & 142.99 & 1 & 142.99 & 95.77 & $<0.0001$ \\
\hline $\mathrm{X}_{2}^{2}$ & 204.88 & 1 & 204.88 & 137.23 & $<0.0001$ \\
\hline $\mathrm{X}_{3}^{2}$ & 314.9 & 1 & 314.9 & 210.92 & $<0.0001$ \\
\hline $\mathrm{X}_{4}^{2}$ & 49.77 & 1 & 49.77 & 33.34 & $<0.0001$ \\
\hline Regression value & 20.9 & 14 & 1.49 & & \\
\hline Missing item & 18.67 & 10 & 1.87 & 3.34 & 0.1282 \\
\hline residual & 2.24 & 4 & 0.56 & & \\
\hline Total residuals & 788.38 & 28 & & & \\
\hline
\end{tabular}




\begin{tabular}{|c|c|c|c|c|}
\hline Response value & Two regression equation & $R^{2}$ & $R_{\mathrm{Adj}}^{2}$ & CV $(\%)$ \\
\hline Collagen protein & $\begin{array}{l}Y=5.37-0.17 X_{1}-0.039 X_{2}-0.091 X_{3}-0.083 X_{4}+0.062 X_{1} X_{2}-0.083 X_{1} X_{3} \\
-0.13 X_{1} X_{4}+0.058 X_{2} X_{3}+0.069 X_{2} X_{4}-0.097 X_{3} X_{4}-0.24_{1}^{2}-0.11 X_{2}^{2} \\
-0.055 X_{3}^{2}-0.089 X_{4}^{2}\end{array}$ & 0.9842 & 0.9683 & 0.70 \\
\hline Polysaccharide & $\begin{array}{l}Y=1.00+0.016 X_{1}+0.027 X_{2}-0.012 X_{3}-0.011 X_{4}+0.025 X_{1} X_{2} \\
-2.5 E-003 X_{1} X_{3}-0.015 X_{1} X_{4}+0.022 X_{2} X_{3}+0.012 X_{2} X_{4}-0.027 X_{3} X_{4} \\
-0.21 X_{1}^{2}-0.013 X_{2}^{2}-0.016 X_{3}^{2}-0.026 X_{4}^{2}\end{array}$ & 0.9868 & 0.9736 & 0.56 \\
\hline Sensory evaluation & $\begin{array}{l}Y=97.97+0.082 X_{1}+0.171 X_{2}+1.96 X_{3}-0.12 X_{4}-2.12 X_{1} X_{2}-0.50 X_{1} X_{3} \\
+3.95 X_{1} X_{4}+4.97 X_{2} X_{3}-1.34 X_{2} X_{4}+0.18 X_{3} X_{4}-4.70_{1}^{2}-5.62 X_{2}^{2} \\
-6.97 X_{3}^{2}-2.77 X_{4}^{2}\end{array}$ & 0.9735 & 0.9470 & 1.36 \\
\hline
\end{tabular}

\section{Conclusion}

In this study, fuzzy mathematics was applied to evaluate the sensory quality of instant sea cucumber. The overall quality of instant sea cucumber was also monitored by measuring its collagen and polysaccharide contents. Our single factor experiments and response surface analysis revealed the following optimal processing conditions: Cooking time, $17 \mathrm{~min}$; cooking temperature, $83^{\circ} \mathrm{C}$; sterilization time, $10 \mathrm{~min}$; and sterilization temperature, $103^{\circ} \mathrm{C}$. Under these conditions, the protein content, polysaccharide content and sensory score were $5.263 \pm 0.020 \%, 1.021 \pm 0.068 \%$ and $97.27 \pm 0.85$, respectively and these findings were consistent with the predicted values. The model could reliably predict the quality of instant sea cucumber products. Worker, processing and equipment requirements were low and the process was simple and easily operated. This study provided a basis for the production of sea cucumber products.

\section{Acknowledgement}

This work was supported by Science and Technology Project of Hebei Province (No. 14273205D), Education Department of Hebei Province (No.YQ2014037), the 'Double First-rate subject-Food Science and Engineering' Program of Heibei Province (2016SPGCA18) and the Program of Young and Top Talents of Hebei Province. The authors declare that they have no competing financial interests.

\section{Author's Contributions}

Jianfeng Sun: Involved in sample preparation, study design, performing in the laboratory work and manuscript writing and revising and scientific discussion.

Tianshu Yang and Qian Liu: Involved in study design, manuscript writing and scientific discussion.

Zhaoping Sun: Involved in manuscript writing.

\section{Ethics}

The authors declare that they have no conflict of interest. All authors have read and approved the manuscript and no ethical issues involved.

\section{References}

Bai, Y., M. Qu, Z. Luan, X. Li and Y. Yang, 2013. Electrohydrodynamic drying of sea cucumber (Stichopus japonicus). LWT-Food Sci. Technol., 54: 570-576. DOI: 10.1016/j.lwt.2013.06.026

Bordbar, S., F. Anwar and N. Saari, 2011. High-Value components and bioactives from sea cucumbers for functional foods-a review. Mar. Drugs, 9: 1761-1805. DOI: $10.3390 / \mathrm{md} 9101761$

Charunuch, C., N. Limsangouan, W. Parsert and P. Butsuwan, 2011. Optimization of extrusion conditions for functional ready-to-eat breakfast cereal. Food Sci. Technol. Res., 17: 415-422. DOI: $10.3136 /$ fstr. 17.415

Conand, C. and M. Byrne, 1993. A review of recent developments in the world sea cucumber fisheries. Mar. Fish. Rev., 55: 1-42. DOI: $10.1111 / \mathrm{j} .1467-2979.2011 .00443 . x$

Eriksson, H. and S. Clarke, 2015. Chinese market responses to overexploitation of sharks and sea cucumbers. Biol. Conserv., 184: 163-173. DOI: $10.1016 /$ j.biocon.2015.01.018

Gao, H. and S. Fu, 2011. Evaluation of jujube beverage prescriptions with fuzzy mathematics. Adv. Mater. Res., 271-273: 573-576.

DOI: 10.4028/www.scientific.net/AMR.271-273.573

$\mathrm{Hu}, \mathrm{X}$. and Y.B. Xia, 2011. An improved sensory comprehensive evaluation method for chopped hot pepper based on fuzzy mathematics. Food Sci., 32: 95-98. DOI: $10.7506 /$ spkx1002-6630-201101023

Ji, C.Y., 1991. The right issuance of weight assignment in the sensory fuzzy comprehensive evaluation. Food Sci., 12: 9-11. 
La, M.P., J.J. Shao, J. Jiao and Y.H. Yi, 2012. Three cerebrosides from the sea cucumber Cucumaria frondosa. Chin. J. Nat. Med., 10: 105-109. DOI: 10.3724/SP.J.1009.2012.00105

Lawrence, A.J., R. Afifi, M. Ahmed, S. Khalifa and T. Paget, 2010. Bioactivity as an options value of sea cucumbers in the egyptian red sea. Conserv. Biol., 24: 217-225. DOI: $10.1111 / \mathrm{j} .1523-1739.2009 .01294 . \mathrm{x}$

Liu, C., J. Dong, J. Wang, X. Yin and Q. Li, 2012. A comprehensive sensory evaluation of beers from the Chinese market. J. Inst. Brew., 118: 325-333. DOI: $10.1002 /$ jib.43

Liu, Y., P. Fang, D. Bian, H. Zhang and S. Wang, 2014. Fuzzy comprehensive evaluation for the motion performance of autonomous underwater vehicles. Ocean Eng., 88: 568-577.

DOI: 10.1016/j.oceaneng.2014.03.013

Mamelona, J., R. Saint-Louis and E.M. Pelletier, 2009. Nutritional composition and antioxidant properties of protein hydrolysates prepared from echinoderm byproducts. Int. J. Food Sci. Tech., 45: 147-154. DOI: $10.1111 / \mathrm{j} .1365-2621.2009 .02114 . \mathrm{X}$

Saito, M., N. Kunisaki, N. Urano and S. Kimura, 2002. Collagen as the major edible component of sea cucumber (Stichopus Japonicus). Food Chem. Toxicol., 67: 1319-1322.

DOI: $10.1111 /$ j.1365-2621.2002.tb10281.x
Song, J.F., C.Q. Liu and D.J. Li, 2012. Process optimization of extraction and separation of watersoluble crude polysaccharide in sweet corn cob. Food Sci. Technol. Res., 18: 631-637.

DOI: $10.3136 /$ fstr. 18.631

Toral-Grand, V., A. Lovatelli and M. Vasconcellos, 2008. Sea cucumber: A global review of fisheries and trade. SPC Beche de Mer Inform. Bull., 516: 4-6.

Wen, J., C. Hu and S. Fan, 2010. Chemical composition and nutritional quality of sea cucumbers. J. Sci. Food Agr., 90: 2469-2474. DOI: 10.1002/jsfa.4108

Xue, D.M., 2006. Study on physical properties and processing technology of sea cucumber. China Ocean University, Qingdao.

Yao, H.H., 2013. Effects of cooking methods on quality characteristics of sea cucumber. Yantai University, Yantai.

Zheng, J., H.T. Wu, X.P. Dong, S. Zhang and M.M. Zhang et al., 2010. Establishment of evaluation indicators for autolysis of sea cucumber based on alteration in main chemical compositions. J. Dalian Polytech. Univ., 29: 391-395.

Zhu, C.P., X.C. Zhai, L.Q. Li, X.X. Wu and B. Li, 2015. Response surface optimization of ultrasoundassisted polysaccharides extraction from pomegranate peel. Food Chem., 177: 139-146. DOI: $10.1016 /$ j.foodchem.2015.01.022 